Available online on 15.08.2020 at http://jddtonline.info
Open Access to Pharmaceutical and Medical Research
unrestricted non-commercial use, provided the original work is properly cited

Open $\odot$ Access

Research Article

\title{
Drug use pattern using WHO prescribing indicators at Sheikh Sultan Hassan Yabere Referral Hospital, Eastern Ethiopia: A cross sectional study
}

\author{
Muktar Shekabdulahi Warsame \\ Jigjiga University, College of Medicine and Health Sciences, Department of Public Health, Ethiopia
}

\begin{abstract}
Introduction: In order to enhance rational drug use, it is very important to assess the prescribing pattern of the facilities using standard prescribing checklists. Hence, the aim of this study was to assess drug use pattern using WHO prescribing indicators at Sheikh Hassan Sultan Yabere Referral Hospital, Eastern Ethiopia.

Objective: the objective of this study is to assess drug use pattern using WHO prescribing indicators at Sheikh Hassan Sultan Yabere Referral Hospital, Eastern Ethiopia 2019

Method: Retrospective study design was employed to assess the current drug prescribing pattern of Sheikh Hassan Sultan Yabere Referral Hospital.Six Month prescription papers from December 1, 2018 to May 31, 2019 were surveyed. A total of 600 prescriptions that were selected using systematic random sampling were reviewed. Data was collected from prescriptions at outpatient pharmacy. The data was entered to excel and analyzed and presented with tables and charts.

Results: The average number of drugs prescribed per encounter or mean was 1.98 with a range between one and six drugs. The percentage of encounters in which an antibiotic or injection prescribed were $60 \%(n=600)$ and $2.5 \%$ ( $n=600)$ respectively. The percentage of drugs prescribed by generic name and from an essential drug list were $89.5 \%(n=600)$ and $98.99 \%$ ( $n=600)$. The commonly prescribed forms of antibiotics were Amoxicillin (19.15\%), Amoxicillin/Clavulunate (17.41) and Azithromycin (16.83\%).The most commonly prescribed injection was Ceftriaxone $(52.14 \%)$.
\end{abstract}

Conclusion: This study revealed major deviation from standard WHO recommended rational prescribing practice with regard to antibiotic use. The study also showed deviation from WHO standard with regard to use of generic name and prescribing from national formulary/Essential drug list.

Keywords: Rational drug use, prescribing pattern, WHO prescribing indicators Jigjiga, Somali Region.

Article Info: Received 07 June 2020; Review Completed 05 July 2020; $\quad$ Accepted 16 July 2020; Available online 15 August 2020

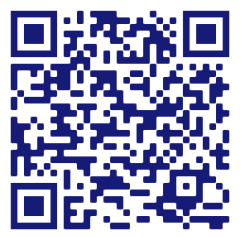

Cite this article as:

Warsame MS, Drug use pattern using WHO prescribing indicators at Sheikh Sultan Hassan Yabere Referral Hospital, Eastern Ethiopia: A cross sectional study, Journal of Drug Delivery and Therapeutics. 2020; 10(4-s):34-38 http://dx.doi.org/10.22270/jddt.v10i4-s.4207

Muktar Shekabdulahi Warsame, Jigjiga University, College of Medicine and Health Sciences, Department of Public Health, Ethiopia. Email: muktarshek66@yahoo.com

\section{INTRODUCTION:}

Medicines play an indispensable role in health care delivery and prevention of disease and are major component of patient management in health care. The availability and affordability of good quality medicines along with their rational use is vital for effective health care.to promote rational drug use, it is important to assess drug use pattern using World health organization(WHO) drug use indicators ${ }^{1}$.

According to world health organization (WHO) half of the medicines are prescribed and dispensed improperly, Hence, half of patients take them inappropriately2.
Essential drugs are those that satisfy the health needs of the majority of the population with a cost which is affordable to the community. These drugs should be present at all times in an adequate amount and dosage form ${ }^{3}$

A study conducted in 8 hospitals in southern Ethiopia on prescribing pattern revealed irrational prescribing of drugs which include high average number of drugs for patients, high presence of antibiotics and injections 4 .

According to study conducted at Ayder Referral hospital the average number of drugs per prescription was 1.67 with a range of one to six. Generic prescribing and drug use from national formulary were $86.6 \%$ and $94 \%$ respectively. The percentage antibiotics and injection use was found to be 
$32.9 \%$ and $41.9 \%$ respectively ${ }^{1}$. Due to the rising prevalence of antibiotic resistance globally, inappropriate antibiotic use is of international concern, and countries struggle to implement basic policies promoting rational antibiotic use ${ }^{5}$.

A study conducted in Nepal Katamandu medical college teaching hospital showed poly pharmacy (Average no. of prescription per encounter was 5.8 )and commonly used brand names for prescribing of the drugs 6

This study assessed the drug prescribing pattern in outpatient pharmacy of Jigjiga University, Sheikh Sultan Hassan Yabere Referral Hospital by using WHO prescribing indicator use.

\section{METHOD}

\section{Study setting}

Jigjiga University, Sheikh Sultan Hassan Yabere Referral Hospital is found in capital city of Somali region,Jigjiga which is located $610 \mathrm{KM}$ east of Addis Abeba capital of Ethiopia. This is the only referral hospital in the region and serves more than five million populations as a referral point including the neighboring countries like Somalia.

\section{Study design}

A retrospective cross sectional study design was employed on outpatient prescription for the period of December 2018May 2019.

\section{Data collection and analysis.}

A total of 600 prescriptions which is minimum standard to study prescribing pattern according to WHO were included in the study. Data collection tools were adopted from WHO prescribing indicators. The specific types of data necessary to measure the prescribing indicators were recorded for each patient encounter which includes information such as age, sex, diagnosis, drug prescribed, injections, Antibiotics and category of the drug.

Prescriptions containing drugs which are not readable and those which contain medical supplies were excluded from the study.

\section{Prescribing indicators}

The prescribing indicators that were measured included:

1. The average number of drugs prescribed per encounter: This measures the rational drug use from poly pharmacy perspective and is calculated by dividing the total number of different drugs prescribed by the number of prescription encounters surveyed. Two or more drugs that are prescribed for a given health condition (e.g. Helicobacter induced pylori) is counted as one.

2. Percentage of drug prescribed by generic name: Measures the tendency of prescribing by generic name and is calculated by dividing the number of drugs prescribed by generic name by total number of drugs prescribed multiplied by 100 .

3. Percentage of encounters in which an antibiotic was prescribed: measures appropriate utilization of antibiotics in treating the diseases. This is calculated by dividing the number of patient encounters in which antibiotic was prescribed by the total number of encounters multiplied by 100.

4. Percentage of encounters with an injection prescribed is calculated to measure overuse of injections and calculated by dividing the number of patient encounter in which an injection was prescribed by the total number of encounters surveyed multiplied by 100 .

5. The percentage of drugs prescribed from an essential drug list (EDL) is calculated to measure the degree to which practices confront to a national drug policy as indicated in the national drug list of Ethiopia. It is calculated by dividing number of products prescribed which are in essential drug list by the total number of drugs prescribed multiplied by 100.

Inclusion: Encounters that took place from December 2018 to to May 2019 were included and referrals and vaccinations were excluded from the study.

\section{Operational definitions}

Generic drugs: International (non-proprietary) name which is agreed by international commission. The essential drug list of Ethiopia is used as a basis to determine drugs as generic or brand name.

Antibiotics: are produced by microorganisms (Fungi, Bacteria) and are directly used against another microorganism at phylogenetic level.In this study drugs such as penicillin, antibacterial, anti-infective dermatological and anti-infective ophthalmic agents are examples of antibiotics.

\section{Ethical consideration}

Ethical approval was obtained from Jigjiga University College of medicine and Health Science and permission was obtained from the hospital to undergo the study. In addition, patients document were kept appropriately and confidentially

\section{RESULTS}

\section{Completeness of prescription}

A total of 600 prescriptions were reviewed from Dec 2018May 2019 in this hospital. 414 (69\%) and 544 (90.67) of the prescriptions contained the date and age of the patients but only $9(1.5 \%)$ and $41(6.83)$ of the prescriptions contained patient weight and address respectively. The diagnosis was also written only for 49 (8.17\%) of the patients.

Most drugs were prescribed from Essential drug list of Ethiopia 1178 (98.99\%) and were mainly prescribed using generic name of drugs 1065 (89.5\%).

Concerning the prescribing indicators, the average number of drugs per encounter was 1.98.Sixty percent $(60 \%)$ of the encounters contained one or more antibiotics and only $2.5 \%$ of encounters contained injections. Majority of the drugs $(89.5 \%)$ were prescribed using generic name which is recommended nationally and almost all (98.99\%) were from the national drug list. (Table 1. Summarizes the main prescribing indicators). 
Table 1: Result of prescribing indicators at Jigjiga University Shiekh Sultan Hassan Yabere Referral Hospital, Somali Region, Jigjiga June 2019.

\begin{tabular}{|c|c|c|c|c|}
\hline S.no. & Prescribing indicators assessed & $\begin{array}{l}\text { Total } \\
\text { drugs/encounters }\end{array}$ & $\begin{array}{l}\text { Average/Percen } \\
\text { tage (\%) }\end{array}$ & $\begin{array}{l}\text { Standard } \\
\text { (Ideal) }\end{array}$ \\
\hline 1. & Average no. of drugs per encounter & 1190 & 1.98 & $1.6-1.8$ \\
\hline 2. & Percentage of encounter with antibiotics & 360 & 60 & $20-26.8 \%$ \\
\hline 3. & Percentage of encounters with injections & 15 & 2.5 & $13.4-24.1$ \\
\hline 4. & Percentage of drugs prescribed by generic name & 1065 & 89.5 & $100 \%$ \\
\hline 5. & Percentage of drugs from the national list & 1178 & 98.99 & $100 \%$ \\
\hline
\end{tabular}

The most commonly prescribed antibiotics were amoxicillin 99 (19.15\%) followed by Amoxicillin+Clavulunate 90 (17.14\%) and Azithromycin 87 (16.83\%) respectively. (Table 2 shows summary of this)

Table 2: Result of most commonly prescribed antibiotics at Jigjiga University Shiekh Sultan Hassan Yabere Referral Hospital, Somali Region, Jigjiga, June 2019.

\begin{tabular}{|c|c|c|c|}
\hline S.no. & Name Antibiotics & Frequency $(\mathrm{N}=517)$ & Percentage (\%) \\
\hline 1. & Amoxicillin & 99 & $19.15 \%$ \\
\hline 2. & Amoxicillin/Clavulunate & 90 & $17.41 \%$ \\
\hline 3. & Azithromycin & 87 & $16.83 \%$ \\
\hline 4. & Metronidazole & 68 & $13.15 \%$ \\
\hline 5. & Ciprofloxacin & 58 & $11.22 \%$ \\
\hline 6. & 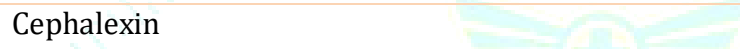 & 28 & $5.42 \%$ \\
\hline 7. & Doxycycline & 20 & $3.87 \%$ \\
\hline 8. & Cloxacillin & 22 & $4.26 \%$ \\
\hline 9. & Norfloxacilin & 13 & $2.51 \%$ \\
\hline 10. & $\begin{array}{l}\text { Others (Ceftriaxone, Cotrimoxazole, Erythromycin, } \\
\text { Ampicillin, Clarithromycin, Cefixime, Benzathin pen.) }\end{array}$ & 32 & $6.2 \%$ \\
\hline
\end{tabular}

The most commonly prescribed injection in this referral hospital was ceftriaxone (11.76\% as shown in table 3$)$

Table 3: Result of most commonly Prescribed Injections at Jigjiga University Shiekh Sultan Hassan Yabere Referral Hospital, Somali Region, Jigjiga June 2019.

\begin{tabular}{|c|l|c|c|}
\hline S.no. & Name of injection & Total & \% \\
\hline $\mathbf{1}$ & Ceftriaxone & 9 & $52.94 \%$ \\
\hline $\mathbf{2}$ & Diclofenac & 2 & $11.76 \%$ \\
\hline $\mathbf{3}$ & Procaine penicillin & 2 & $11.76 \%$ \\
\hline $\mathbf{4}$ & Cimetidine & 1 & $5.88 \%$ \\
\hline $\mathbf{5}$ & Metocloperamide & 1 & $5.88 \%$ \\
\hline $\mathbf{6}$ & Benzatin penc. & 1 & $5.88 \%$ \\
\hline $\mathbf{7}$ & Hydrocortisone & 1 & $5.88 \%$ \\
\hline & Total & 17 & $100.00 \%$ \\
\hline
\end{tabular}

Among the drugs prescribed, the most commonly prescribed categories of drugs were antibiotics 476 (41.11\%) followed by Anti-inflammatory and Cardiovascular drugs 
Table 4: Result of Prescribed category of drugs at Jigjiga University Shiekh Sultan Hassan Yabere Referral Hospital, Somali Region, Jigjiga June 2019.

\begin{tabular}{|c|c|c|c|}
\hline S.no. & Category of drugs & Total & $N=1158$ \\
\hline 1. & Antibiotics & 476 & $41.11 \%$ \\
\hline 2. & GI drugs & 86 & $7.43 \%$ \\
\hline 3. & CV \& Kidney drugs & 94 & $8.12 \%$ \\
\hline 4. & Antiprtozoals & 21 & $1.81 \%$ \\
\hline 5. & Antihelmints & 19 & $1.64 \%$ \\
\hline 6. & Antipians \& Antirhematics & 245 & $21.16 \%$ \\
\hline 7. & Anti-Asthma \& Other respiratory drugs & 48 & $4.15 \%$ \\
\hline 8. & Vitamins \& Minerals & 93 & $8.03 \%$ \\
\hline 9. & Antidiabetic \& Endocrine drugs & 20 & $1.73 \%$ \\
\hline 10. & NS drugs \& Anesthetics & 26 & $2.25 \%$ \\
\hline 11. & Antifungals & 14 & $1.21 \%$ \\
\hline 12. & Ophthalmic agents & 10 & $0.86 \%$ \\
\hline 13. & Anticogulants & 2 & $0.17 \%$ \\
\hline 14. & Antiviral & 4 & $0.35 \%$ \\
\hline & Total & 1158 & $100 \%$ \\
\hline
\end{tabular}

Most drugs were prescribed by oral route of drug administration and followed by topical route.

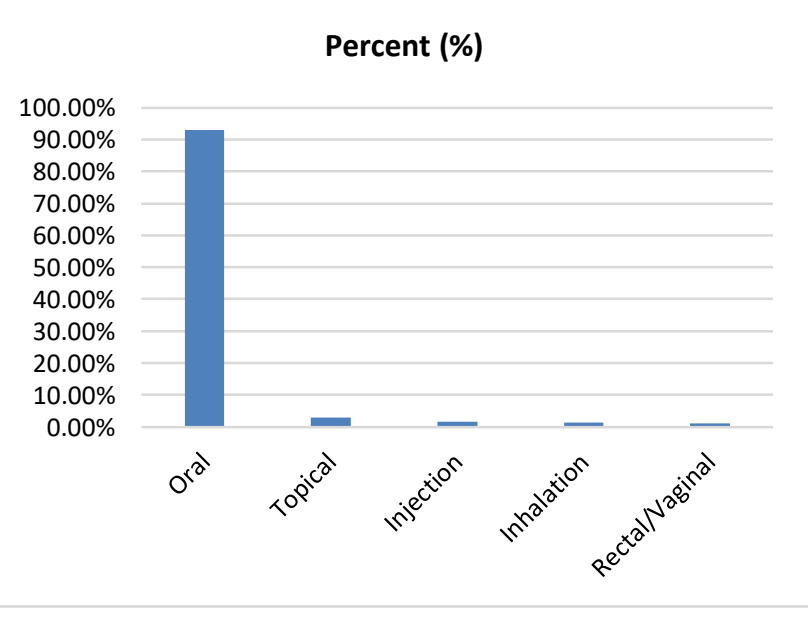

Figure 1: Commonly prescribed route of drug administration at Jigjiga University Shiekh Sultan Hassan Yabere Referral Hospital, Somali Region, Jigjiga June 2019.

\section{DISCUSSION}

In this study the average number of drugs per prescription was 1.98 which is not far from the standard (1.6-1.8) \& is similar with similar study conducted at Hawassa University Refferal hospital but is lower than study conducted in selected hospitals in eastern Ethiopia which was 2.2 7, 8 . Study conducted at South west Ethiopia in Jimma hospital showed average prescriptions per encounter of 1.59 But, in another study at Northern Ethiopia on three hospitals the average prescriptions per encounter were 0.98 at Gonder, 1.8 at Bahirdar and 2.2 at Debre Tabor hospital respectively 9,10 .

Study conducted at Jordan on five hospitals reveled 2.93 drugs per prescription and another study at Nigeria on hospitalized children showed an average encounter of 2.1 drugs per prescription ${ }^{11,12}$.

Other study conducted on 209 patients at South India pediatric population showed the average number of drugs per prescription of 4.56 and in Pakistan it was 2.8 13, 14

In this study Sixty percent $(60 \%)$ of the encounters contained one or more antibiotics which is comparable with study at Hawassa University Hospital (58\%) and very high compared to the standards ${ }^{8}$. This should be given emphasis and regulated for better patient outcome. A higher percentage of encounters in the use of antibiotics (exceeding proposed reference values) may potentially be signifying an indiscriminate use of antibiotics. While a high antibiotic use may highlight increased rate of local infections, it may be a sign of prescriber's inexperience or a weak local health system characterized by a lack of diagnostic facilities such as microscopes that often lead to presumptive treatment of cases

In this study, only $2.5 \%$ of encounters contained injections which is lower than the standard as well as that of Hawassa University Hospital study(38.1\%) and study conducted in selected health facilities in eastern Ethiopia which was $11.3 \%{ }^{7,8}$

Most commonly prescribed antibiotics was similar with Hawassa University hospital study (I.e. ammoxacillin, $19.15 \%$,) followed by ammoxacillin+clavulunate $(17.41 \%)$ and azithromycin $(16.87 \%)^{8}$.

The proportion of medicines prescribed by generic name was $89.5 \%$ and about $99 \%$ of drugs were prescribed from essential drug list of Ethiopia. In study conducted in selected hospitals in Eastern Ethiopia \% by generic name and from essential drug list (EDL) were 97\% and $92 \%$ respectively ${ }^{7}$. In other study conducted at the Hawassa University Hospital the $\%$ prescribed by generic name was $98.7 \%$ and $96.6 \%$ were from the essential drug list of Ethiopia but in the study 
conducted in Northern Nigeria only $66.8 \%$ of the drugs were written with generic names and $95.5 \%$ of the drugs were prescribed from the Essential medicine list ${ }^{8,12}$.

In other study conducted in Jordan and India prescribing from the essential drug list was $57.6 \%$ and $49.78 \%$ respectively. In addition the drugs prescribed by generic name was found to be only $19.16 \%$ in the Indian study 11,15 .

Percentage of medicines prescribed generically as well as from EML highlights conformity to lay down prescribing regulations and prevailing medicines situation. For instance, a low percentage of generic medications prescribed may signal unavailability of cost-effective generic medicines because of potency issues, prescriber's lack of confidence in generic medicines and/or patients preference for branded products.

In this study, the most commonly prescribed antibiotics were amoxicillin $99(19.15 \%)$ followed by Amoxicillin+ Clavulunate 90 (17.14\%) and Azithromycin 87 (16.83\%) respectively. And the most commonly prescribed injection in this referral hospital was ceftriaxone $(11.76 \%)$. This was similar to study conducted in Jordan where amoxicillin was most commonly prescribed antibiotics. In study conducted in Nigeria the most commonly used choice of antibiotic were ampicillin/cloxacillin combination 11,12 .

In this study antibiotics were the most commonly prescribed category of drugs and most drugs were prescribed by oral route of drug administration and followed by topical route. This was similar to study conducted in Arba minch General hospital and Chenka hospital and Tamil Nadu 13,16.

\section{Limitations of this study}

The WHO prescribing indicators were used in this study which records exactly what was prescribed to the patients, but not why which may need further study. They are designed for use in health centers, dispensaries or hospital outpatient departments and are less useful in referral hospitals where the drug use pattern is more complex.

\section{CONCLUSION}

In this study there was no deviation from standard of prescription per encounter which assesses the presence of poly pharmacy in the facility but observed major deviation (overuse) from standard WHO recommended rational prescribing practice with regard to antibiotic use which may need an intervention. Drug use evaluation on whether these antibiotics prescribed correctly or not should be done.

The study also showed deviation from WHO standard with regard to use of generic name and prescribing from national formulary/Essential drug list.

Baseline from this study can be used by researchers and policy makers to improve prescribing practice at this referral hospital.

\section{Recommendations}

Based on the findings of this study the following recommendations are forwarded

The Referral hospital should take measures for correcting deviation from the standard with regard to antibiotics and injections through different means
$>$ The health workers should be adhering to the standard in their prescribing using generic drugs and awareness on this should be provided to the health workers

$>$ Further study should also be done to dig out factors contributing irrational drug uses.

\section{Acknowledgments}

I would like to pass my gratitude for Jigjiga University Sheikh Hassan Sultan Yare Referral hospital staff for their support during the study and the data collection. I would also like to pass my thanks to data collectors for their continuous effort during the data collection

\section{Competing Interests}

There is no financial or personal relationship(s) which may have inappropriately influenced me in writing this article.

\section{REFERENCES}

1. Legese B. Assessment of Drug Use Pattern Using Who Prescribing And Patient Care Indicators In A Referral Hospital In Ethiopia. Value in Health. 2015; 18(7):A564

2. (1987) W. The Rational use of drugs: report of the conference of experts, Nairobi. 1985 25-29 November. Report No.

3. WHO. The use of Essential Drugs. 6th Report of the Expert Committee. WHO Technical Report Geneva: 1995.

4. Debalto D GZ, Teklemariam S:. A base line survey of prescribing indicators and factors influencing prescribing in souther $n$ Ethipia. . J Health Dev. 1991; 11(3):263-7.

5. Le Doare K1 BC, Irwin A, Sharland M. Improving antibiotic prescribing for children in the resource-poor setting. Br J Clin Pharmacol 2015; 79(3):446-55. .

6. Binaya Shrestha SMD. Assessment of Drug Use Pattern Using WHO Prescribing Indicators. J Nepal Health Res Counc 2018; 16(40):279-84.

7. Bilal Arebu I DI, Mulugeta A. Assessment of medicines use pattern using World Health Organization's Prescribing, Patient Care and Health facility indicators in selected health facilities in eastern Ethiopia BMC Health Services Research 2016; 16:144.

8. Desalegn. Assessment of drug use pattern using WHO prescribing indicators at Hawassa University Teaching and Referral Hospital, South Ethiopia: A cross-sectional study. BMC Health Services Research. 2013; 13:170.

9. Abdulahi M ST. Pattern of prescription in Jimma Hosptial. Ethiop J Health Dev 1997; 11(3):263-7.

10. Desta Z AT, Gebre-Yohannes A, Worku A:. Drug prescribing pattens for outpatients in three hospitals in north-west Ethiopia. Ethiop J Health Dev 2002; 16(2):183-9.

11. Al-Azayzih A A-AS, Alzoubi KH, Shawaqfeh M, Masadeh MM. Evaluation of drug-prescribing patterns based on the WHO prescribing indicators at outpatient clinics of five hospitals in Jordan: a cross-sectional study. Int J Clin Pharmacol Ther 2017; 55(5):425-32.

12. Umar LW IA, Musa S, Umar B. Prescribing pattern and antibiotic use for hospitalized children in a Northern Nigerian Teaching Hospital. Ann Afr Med. 2018; 17(1):26-32.

13. Gopalakrishnan S1 GP, Katta A. Assessment of prescribing practices among urban and rural general practitioners in Tamil Nadu. Indian J Pharmacol. 2013; 45(3):252-7.

14. Atif M SM, Azeem M, Umer D, Rauf A, Rasool A, Ahsan M, Scahill S. Assessment of WHO/INRUD core drug use indicators in two tertiary care hospitals of Bahawalpur, Punjab, Pakistan. J Pharm Policy Pract 2016; 9(27).

15. Thiruthopu NS1 MU, Bairi R3, Sivva D1, Martha S4. Drug utilization pattern in South Indian pediatric population: A prospective study. NCBI. 2014; 5(4):178-83. .

16. Mensa M TT, Ayele A. Assessment of Drug Use Pattern by Using WHO Core Drug Use Indicators at Public Hospitals in Ethiopia. . J Community Med Health Educ 2017; 7:559. 